\title{
Effect of preozonation on the filterability of model dairy waste water in nanofiltration
}

\author{
Zsuzsanna László, Szabolcs Kertész, Sándor Beszédes, \\ Zsuzsanna Hovorka-Horváth, Gábor Szabó, Cecilia Hodúr* \\ Department of Technical and Process Engineering, Faculty of Engineering, University of Szeged, \\ H-6725, Szeged, Moszkvai krt. 5-7, Hungary \\ Tel.+3662 546037; Fax+3662 546549; email: zsizsu@sol.cc.u-szeged.hu, hodur@mk.u-szeged.hu
}

Received 22 August 2007; revised 29 November 2007; accepted 5 December 2007

\begin{abstract}
Model dairy waste waters (prepared from milk powder by dilution) were treated with ozone, and the effects of the ozonation time and the surfactant concentration on the flux, the membrane resistances, membrane fouling and gel formation were measured. It was found that the microflocculation effect of ozone may play a significant role at a higher gas flow rate, causing a decreased level of fouling and increased gel formation, while at a lower flow rate the effect of the degradation of large molecules was more marked, causing a higher flux, but decreasing the retention.
\end{abstract}

Keywords: Ozonation; Nanofiltration; Chemical oxygen demand; Microflocculation; Shapiro-Wilk test

\section{Introduction}

The importance of the treatment of water and wastewater is steadily increasing because of the ever greater demands to eliminate environmental pollution. Dairy waste waters contain mainly milk residues, proteins, carbohydrates, fats and residual cleaning agents [1]. Membrane filtration is an effective method for decreasing the chemical

*Corresponding author. oxygen demand (COD) caused by the presence of proteins, carbohydrates and surfactants in dairy waste water $[2,3]$. The proteinaceous materials in dairy waste water have been found to act as severe foulants of existing membrane materials, while the surfactants may change the filterability by concentration polarization or micelle formation $[4,5]$. These effects hamper the industrial application of this technique.

Ozone is a powerful oxidant which oxidizes the organic compounds in waste water. Earlier

Presented at the Third Membrane Science and Technology Conference of Visegrad Countries (PERMEA), Siofok, Hungary, 2-6 September 2007. 
studies showed that a preozonation process can improve the total organic carbon content and COD or the turbidity removal during the later filtration or coagulation/flocculation [6].

The aim of the present investigation was to examine the applicability of coupled preozonation and membrane filtration in dairy waste water treatment technology. Model dairy waste waters (prepared from milk powder by dilution) were treated with ozone, and the effects of the ozonation time and the surfactant concentration on the flux, the membrane resistance, membrane fouling and gel formation were measured.

\section{Materials and methods}

Model waste water was prepared from skim milk powder $\left(3 \mathrm{~g} \mathrm{dm}^{-3}\right)$. In the experiments, Chemipur CL80 was added to the model solution as an anionic surfactant cleaning agent in a concentration of $0.01 \mathrm{~g} \mathrm{dm}^{-3}$. The skim milk powder and the cleaning agent Chemipur CL80 (used for cleaning dairy equipment) were provided by Tolnatej Rt. and Sole Hungaria Rt. (Szeged, Hungary), respectively. Ozone was produced from oxygen (Linde 3.0) with a flowtype ozone generator (Ozomatic Modular 4, Wedeco Ltd., Germany) operating via a silent electric discharge. The ozone-containing gas (flow rate 1.0 or $0.5 \mathrm{dm}^{3} \mathrm{~min}^{-1}$ ) was bubbled continuously through a $6.0 \mathrm{dm}^{3}$ batch reactor during the 1-h treatment. The ozone concentration in the bubbling gas was $30 \mathrm{mg} \mathrm{dm}^{-3}$. The COD was determined in test tubes (Lovibond, Germany) with an ET 108 digester (Lovibond, Germany) and a PC CheckIt photometer (Lovibond, Germany). The nanofiltration measurements were carried out on a Uwatech 3DTA laboratory cross-flow membrane filter (Uwatech Gmbh., Germany), with the use of a flat sheet standard DL composite nanofiltration membrane (theoretical $\mathrm{MgSO}_{4}$ retention 96\%) with a filtering surface area of $0.0156 \mathrm{~m}^{2}$. The applied cross-flow velocity was $4.6 \mathrm{~m} \mathrm{~s}^{-1}$. The pressure applied was $3.0 \mathrm{MPa}$; the measurements were carried out at $25^{\circ} \mathrm{C}$, the feed was thermostated, and the temperature was checked before and after the membrane filter. Between each run, the membranes were washed with distilled water until the pure water flux reached the initial value measured after compaction $( \pm 2 \%)$. In each run $2 \mathrm{dm}^{3}$ solution was filtered, the filtration time was $5400 \mathrm{~s}$.

In the literature, the following equation is generally accepted for the flux calculation in NF [7-9]:

$J=\frac{\mathrm{d} V}{\mathrm{~d} \tau} \frac{1}{A}=K_{\mathrm{M}}(\Delta p-\Delta \pi)$

where $J$ is the flux $\left(\mathrm{m}^{3} \mathrm{~m}^{-2} \mathrm{~s}^{-1}\right), A$ is the surface area of the filter $\left(\mathrm{m}^{2}\right), V$ is the filtration volume $\left(\mathrm{m}^{3}\right), \tau$ is time $(\mathrm{s}), K_{\mathrm{M}}$ is the permeability coefficient $\left(\mathrm{m}^{3} \mathrm{~m}^{-2} \mathrm{~s}^{-1} \mathrm{~Pa}^{-1}\right), \Delta p$ is the pressure difference between the two sides of the membrane $(\mathrm{Pa})$ and $\Delta \pi$ is the osmotic pressure difference across the membrane $(\mathrm{Pa})$.

The membrane resistance $\left(R_{\mathrm{M}}\right)$ was calculated as

$R_{\mathrm{M}}=\frac{\Delta p}{J_{\mathrm{W}} \eta}\left(\mathrm{m}^{-1}\right)$

where $J_{\mathrm{W}}$ is the flux of clear water $\left(\mathrm{m}^{3} \mathrm{~m}^{-2}\right.$ $\left.\mathrm{h}^{-1}\right), \eta$ is the water viscosity at $25^{\circ} \mathrm{C}$. The fouling resistance $\left(R_{\mathrm{F}}\right)$ of the membrane can be measured by washing the gel layer from the

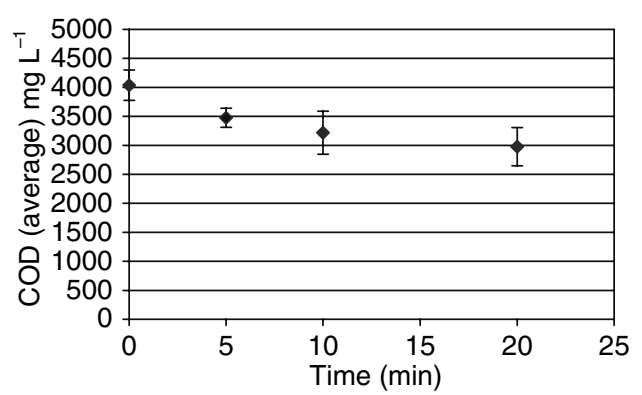

Fig. 1. The changes of COD during ozonation. 
Table 1

The results of Shapiro-Wilk test for data

\begin{tabular}{|c|c|c|c|c|c|c|c|c|}
\hline & \multicolumn{8}{|c|}{$p$-Level } \\
\hline & \multicolumn{4}{|l|}{ Time } & \multicolumn{2}{|c|}{ Flow rate of bubbling gas } & \multicolumn{2}{|c|}{ Detergent content } \\
\hline & $0 \min$ & $5 \mathrm{~min}$ & $10 \mathrm{~min}$ & $20 \mathrm{~min}$ & 0.5 LPM & $1 \mathrm{LPM}$ & $0.0 \mathrm{~g} \mathrm{~L}^{-1}$ & $0.01 \mathrm{~g} \mathrm{~L}^{-1}$ \\
\hline$J / J_{\mathrm{W}}$ & 0.123 & 0.231 & 0.213 & 0.850 & 0.747 & 0.523 & 0.575 & 0.432 \\
\hline$R_{\mathrm{F}}$ & 0.073 & 0.664 & 0.176 & 0.235 & 0.365 & 0.580 & 0.695 & 0.075 \\
\hline$R_{\mathrm{G}}$ & 0.085 & 0.373 & 0.844 & 0.312 & 0.507 & 0.471 & 0.547 & 0.088 \\
\hline$R \%$ & 0.124 & 0.235 & 0.742 & 0.564 & 0.321 & 0.742 & 0.167 & 0.070 \\
\hline
\end{tabular}

membrane. $R_{\mathrm{F}}$ and the resistance of the gel layer $\left(R_{\mathrm{G}}\right)$ can be calculated as

$R_{\mathrm{F}}=\frac{\Delta p}{J_{\mathrm{W}} \eta}-R_{\mathrm{M}}\left(\mathrm{m}^{-1}\right)$ and

$R_{\mathrm{G}}=\frac{\Delta p}{J_{\mathrm{W}} \eta}-R_{\mathrm{M}}-R_{\mathrm{F}}\left(\mathrm{m}^{-1}\right)$

where $\eta$ is the viscosity of the filtered solution at $25^{\circ} \mathrm{C}$.

The selectivity of a membrane for a given solute was expressed by the average (apparent) retention $(R)$ :

$R \%=\left(1-\frac{c}{c_{0}}\right) 100(\%)$

where $c$ is the average concentration of the solute in the permeate phase $\left(\mathrm{mg} \mathrm{COD} \mathrm{dm}^{-3}\right)$, and $c_{0}$ is the concentration of the solute in the bulk solution $\left(\mathrm{mg} \mathrm{COD} \mathrm{dm}{ }^{-3}\right)$. The data were analyzed by three-way analysis of variance (ANOVA).

\section{Results and discussion}

\subsection{The changes of COD during ozonation}

The results of COD measurements during ozone treatment showed that the COD was decreased significantly after ozone treatment for $5 \mathrm{~min}$. Longer treatment caused a further, but not significant, decrease in COD (Fig. 1).

In order to determine whether the flow rate of the ozone-containing bubbling gas or the detergent content had a significant effect on COD, two-way ANOVA was performed. The results demonstrated that none of these factors affected COD significantly.

Table 2

The results of the Cochran test

\begin{tabular}{|c|c|c|c|c|c|c|}
\hline & \multicolumn{6}{|l|}{ Factor } \\
\hline & \multicolumn{2}{|l|}{ Time } & \multicolumn{2}{|c|}{ Flow rate of bubbling gas } & \multicolumn{2}{|c|}{ Detergent content } \\
\hline & $C$ value & $p$-Level & $C$ value & $p$-Level & $C$ value & $p$-Leve \\
\hline$J / J_{\mathrm{W}}$ & 0.331 & 0.710 & 0.772 & 0.121 & 0.755 & 0.161 \\
\hline$R_{\mathrm{F}}$ & 0.472 & 0.675 & 0.825 & 0.056 & 0.760 & 0.152 \\
\hline$R_{\mathrm{G}}$ & 0.395 & 0.782 & 0.629 & 0.501 & 0.772 & 0.136 \\
\hline$R \%$ & 0.567 & 0.320 & 0.691 & 0.304 & 0.652 & 0.412 \\
\hline
\end{tabular}


Table 3

Results of ANOVA

\begin{tabular}{|c|c|c|c|c|c|c|}
\hline & \multicolumn{6}{|l|}{ Factor } \\
\hline & \multicolumn{2}{|l|}{ Time } & \multicolumn{2}{|c|}{ Flow rate of bubbling gas } & \multicolumn{2}{|c|}{ Detergent content } \\
\hline & $F$ value & $p$-Level & $F$ value & $p$-Level & $F$ value & $p$-Level \\
\hline$J / J_{\mathrm{W}}$ & 1.055 & 0.411 & 3.229 & 0.103 & 2.753 & 0.129 \\
\hline$R_{\mathrm{F}}$ & 3.818 & 0.047 & 1.093 & 0.320 & 5.001 & 0.049 \\
\hline$R_{\mathrm{G}}$ & 2.231 & 0.147 & 3.376 & 0.096 & 1.379 & 0.267 \\
\hline$R \%$ & 7.259 & 0.007 & 0.038 & 0.758 & 8.684 & 0.015 \\
\hline
\end{tabular}

\subsection{The changes of membrane filtration parameters after ozonation}

After the ozone treatment $(5,10$ or $20 \mathrm{~min}$ treatment time, with 0.5 or 1 LPM flow rate of bubbling gas) the samples were nanofiltered; the

$$
\text { (a) }
$$

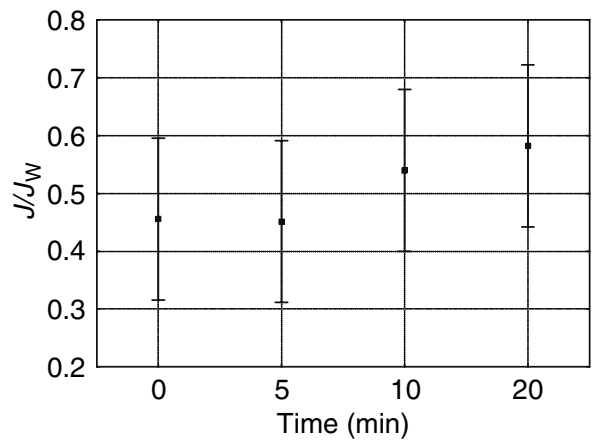

(c)

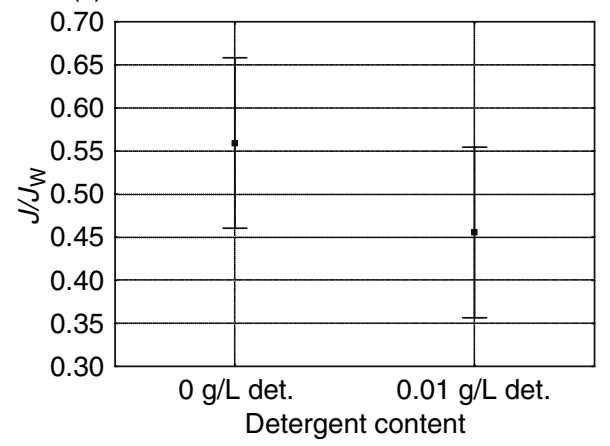

changes of flux, fouling and gel layer resistance and the retention were examined. The data were analyzed by three-way analysis of variance (ANOVA): the effect of ozonation time, the flow rate of bubbling gas and the detergent

(b)

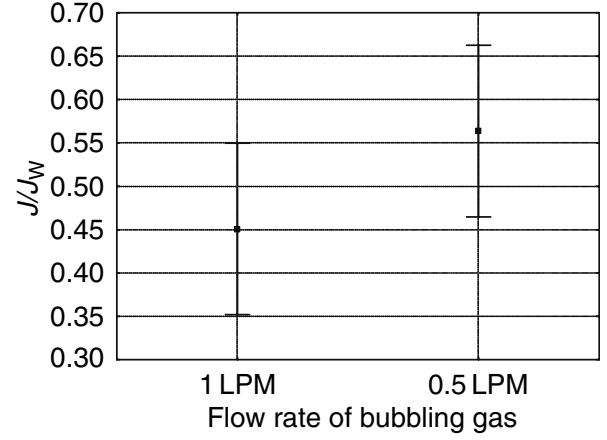

Fig. 2. The change in flux (relative to a pure water flux, $J / J_{\mathrm{w}}$ ) after ozonation. The data obtained at a given the effect of ozonation time during nanofiltration (a), flow rate of bubbling gas (0.5 LPM or 1 LPM) (b) and at a given detergent content $\left(0\right.$ or $\left.0.01 \mathrm{~g} \mathrm{dm}^{-3}\right)$ (c) subjected to ANOVA (averages with 0.95 confidence intervals). 
concentration were analyzed. The Shapiro-Wilk test was used to control conform of data to a Gaussian distribution. The homogeneity of variances in the different groups was checked using Cochran test.

Table 1 presents the results of Shapiro-Wilk tests. It can be established that values conformed to a Gaussian distribution. Then the homogeneity of variances of the data was investigated. The results of Cochran test can be seen in Table 2 . The values demonstrate homogeneity of variances in all cases. So the ANOVA was useful to evaluate data (Table 3 ).

It was found that the 5-min ozonation decreased the flux in the absence of detergent, in accordance with the findings of others and our own earlier results [10,11], which can be

(a)

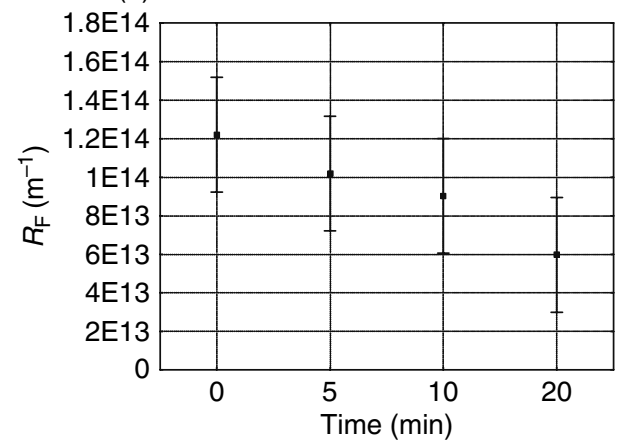

(c)

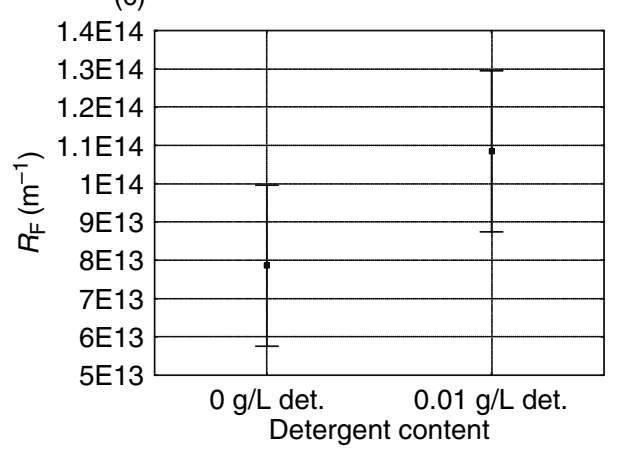

explained by the microflocculation effect of ozone. The longer treatment times may cause the degradation of large molecules, the small molecules get across the membrane, the flux increased (Fig. 2(a)). A perceptible effect was observed for the bubbling gas flow rate: a high flow rate did not change the flux of the untreated samples, while a low flow rate for the bubbling gas resulted in an increased flux (Fig. 2(b)). At lower flow rate more ozone can be dissolved in the solution, thus this effect is similar to the effect of longer ozonation times. During nanofiltration, the average flux of the surfactantcontaining ozone treated samples was lower than in surfactant-free solutions (Fig. 2(c)).

The effects of ozonation time, detergent content and ozone gas flow rate on membrane

(b)

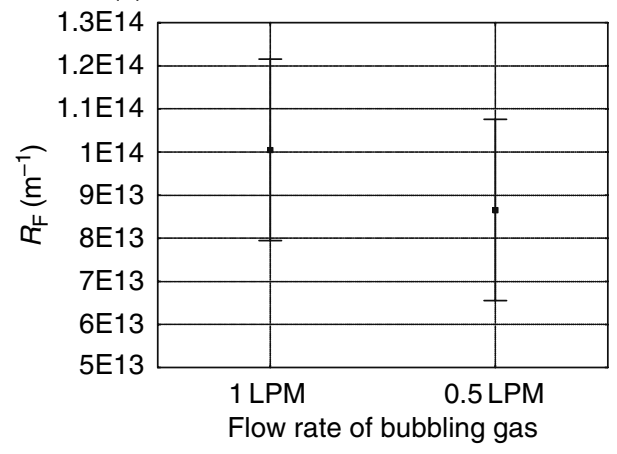

Fig. 3. Changes in membrane fouling resistances after ozonation. The data obtained at a given the effect of ozonation time during nanofiltration (a), flow rate of bubbling gas (0.5 LPM or 1 LPM) (b) and at a given detergent content (0 or $0.01 \mathrm{~g} \mathrm{dm}^{-3}$ ) (c) subjected to ANOVA (averages with 0.95 confidence intervals). 
(a)

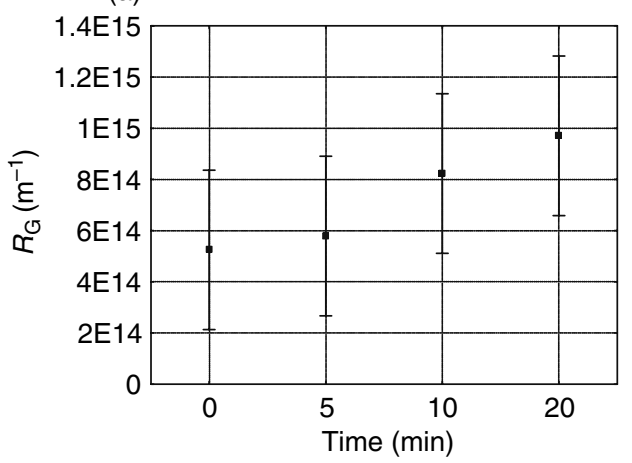

(c)

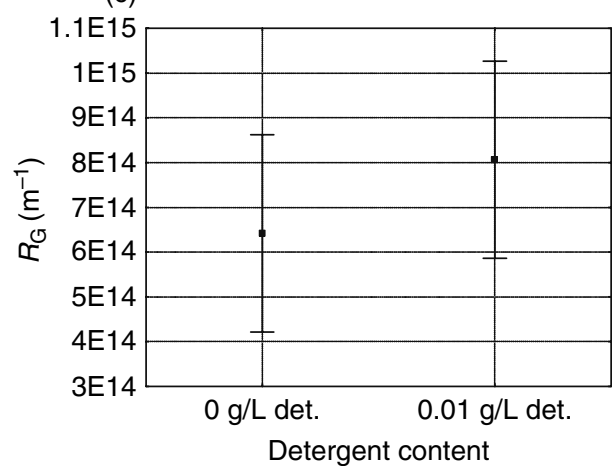

(b)

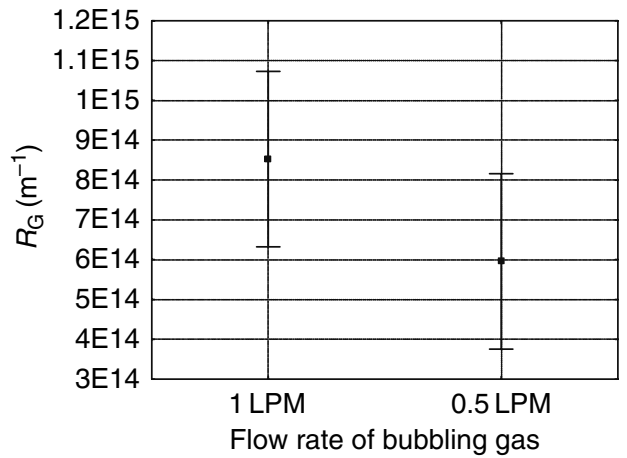

Fig. 4. Changes in membrane gel formation resistances after ozonation. The data obtained at a given the effect of ozonation time during nanofiltration (a), flow rate of bubbling gas (0.5 LPM or 1 LPM) (b) and at a given detergent content $\left(0\right.$ or $\left.0.01 \mathrm{~g} \mathrm{dm}^{-3}\right)$ (c) subjected to ANOVA (averages with 0.95 confidence intervals).

fouling and gel formation were also determined. Ozonation decreased the fouling (Fig. 3(a)); however, this was less significant in the presence of detergent. It was found that the presence of detergent increased the extent of fouling (Fig. 3 (c)). The lower flow rate of bubbling gas led to a decrease in fouling (Fig. 3(b)). These results are in accordance with the changes of flux.

It is noteworthy that while the ozonation decreased the extent of fouling it increased the gel formation resistance (Fig. 4(a)). This can be explained by the microflocculation effect of ozonation; the microflocs could not foul the membrane pores, because they form a layer on the surface of the membrane. The analysis of the effect of the detergent content on gel formation revealed that the presence of detergent increased the gel formation resistance (Fig. 4(c)); nevertheless, ozonation increased gel formation in detergent-containing solutions, while it did not affect $R_{\mathrm{G}}$ in the absence of detergent. This means that the gel layer formed mainly from the detergent-containing micelles, and not from the compounds of pure milk. The higher flow rate, but not the lower flow rate, also increased the gel formation perceptibly, which can be explained that at higher flow rate less ozone dissolved in the solution, the organic compounds cannot be degraded, thus more micelle can be formed (Fig. 4(b)).

These results were corroborated by examining the retention during nanofiltration (Fig. 5). 
(a)

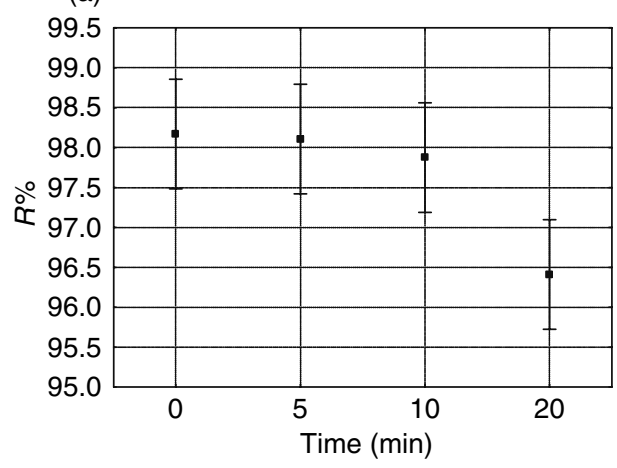

(c)

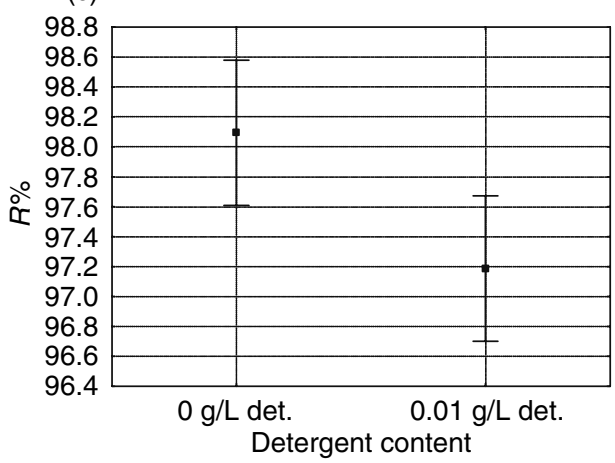

(b)

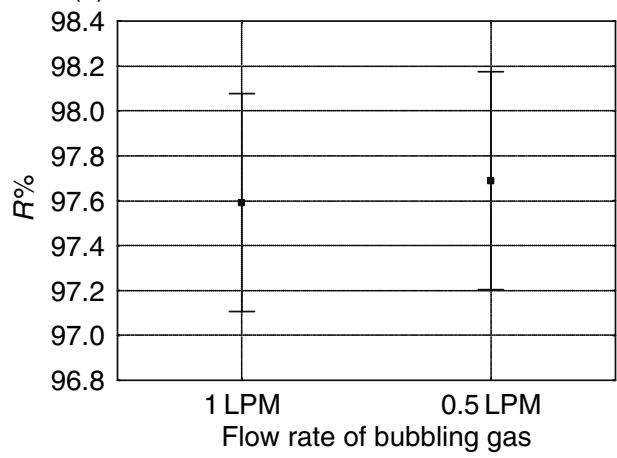

Fig. 5. Changes in membrane retention after ozonation. The data obtained at a given the effect of ozonation time during nanofiltration (a), flow rate of bubbling gas $(0.5 \mathrm{LPM}$ or $1 \mathrm{LPM})$ (b) and at a given detergent content $\left(0\right.$ or $\left.0.01 \mathrm{~g} \mathrm{dm}^{-3}\right)$ (c) subjected to ANOVA (averages with 0.95 confidence intervals).

It was found that the retention was decreased after a 20-min ozone treatment (Fig. 5(a)). The presence of detergent worsened the retention, which was also the situation during ozonation. This can be explained by the degradation of the large molecules in the waste water, the resulting small molecules being able to pass through the membrane.

\section{Conclusions}

Analysis of the effects of the ozonation time, detergent content and the bubbling gas flow rate during ozonation on various membrane filtration parameters demonstrated that both affected the flux and the membrane fouling by flocculation. The results indicated that the microflocculation effect of ozone can play a significant role at higher gas flow rate, with a decrease in membrane fouling and an increase in gel formation; at a lower flow rate, the effect of the degradation of large molecules is more pronounced, causing a higher flux, and decreasing membrane resistances. The detergent content may increase the extent of fouling and gel formation, but it did not change the flux.

\section{Acknowledgements}

The authors are grateful to the National Research and Technology Institute (NKTH) and the Research and Development Competition and Research Utilization Agency (KPI) grant (RET-07/2005). 


\section{References}

[1] K.R. Marshall, The characteristics of effluents from New Zealand dairy factories, Bull. Ind. Dairy Fed., 104 (1978) 123-126.

[2] I. Galambos, M.J. Mora, P. Jaray, Gy. Vatai and E. Bekassy-Molnar, High organic content industrial wastewater treatment by membrane filtration, Desalination, 162 (2004) 117-120.

[3] B. Balannec, G. Gesan-Guiziou, B. Chaufer, M. Rabiller-Baudry and G. Daufin, Treatment of dairy process waters by membrane operations for water reuse and milk constituents concentration, Desalination, 147 (2002) 89-94.

[4] S. Judd, B. Jefferson, Membranes for Industrial Waste Water Recovery and Re-use, Elsevier Science Ltd., Amsterdam, 2003.

[5] B. Wendler, B. Goers and G. Wozny, Nanofiltration of solutions containing surfactants - reduction of flux decline and modelling of mass transfer, Desalination, 147 (2002) 217-221.

[6] X. Ntampou, A.I. Zouboulis and P. Samaras, Appropriate combination of physico-chemical methods (coagulation/flocculation and ozonation) for the efficient treatment of landfill leachates, Chemosphere, 62 (2006) 722-730.

[7] Z.V.P. Murthy and S.K. Gupta, Estimation of mass transfer coefficient using a combined nonlinear membrane transport and film theory model, Desalination, 109 (1997) 39-49.

[8] V.K. Gupta, S.T. Hwang, W.B. Krantz and A.R. Greenberg, Characterization of nanofiltration and reverse osmosis membrane performance for aqueous salt solutions using irreversible thermodynamics, Desalination, 208 (2007) 1-18.

[9] Sz. Banvolgyi, I. Kiss, E. Bekassi-Molnar and Gy. Vatai, Concentration of red wine by nanofiltration, Desalination, 198 (2006) 8-15.

[10] H. Hyung, S. Lee, J. Yoon and Ch.-H. Lee, Effect of preozonation of flux and water quality in ozonation-ultrafiltration hybrid system for water treatment, Ozone Sci. Eng., 22 (2000) 637-652.

[11] Zs. László, Sz. Kertész, E. Mlinkovics and C. Hodúr, Dairy waste water treatment by combining ozonation and nanofiltration, Sep. Sci. Technol., 42(7) (2007) 1627-1637. 